\title{
Monosodium Urate Crystals Activate the Inflammasome in Primary Progressive Multiple Sclerosis
}

\author{
Federica Piancone ${ }^{*}$, Marina Saresella ${ }^{1}$, Ivana Marventano ${ }^{1}$, Francesca La Rosa ${ }^{1}$, \\ Maria Antonia Santangelo ${ }^{2}$, Domenico Caputo $^{3}$, Laura Mendozzi ${ }^{3}$, Marco Rovaris ${ }^{3}$ \\ and Mario Clerici ${ }^{1,4}$
}

${ }^{1}$ Laboratory of Molecular Medicine and Biotechnology, Don Gnocchi Foundation, IRCCS, Milan, Italy, ${ }^{2}$ Laboratory of Clinical Analysis, Don Gnocchi Foundation, IRCCS, Milan, Italy, ${ }^{3}$ Department of Neurology, Don Gnocchi Foundation, IRCCS, Milan, Italy, ${ }^{4}$ Department of Physiopathology and Transplants, University of Milano, Milan, Italy

OPEN ACCESS

Edited by: Jens Geginat, Istituto Nazionale Genetica Molecolare (INGM), Italy

Reviewed by:

Richa Hanamsagar, Harvard Medical School, United States Elisabetta Volpe, Fondazione Santa Lucia (IRCCS), Italy

*Correspondence:

Federica Piancone fpiancone@dongnocchi.it

Specialty section: This article was submitted to Multiple Sclerosis and Neuroimmunology, a section of the journal

Frontiers in Immunology

Received: 22 December 2017 Accepted: 20 April 2018 Published: 04 May 2018

Citation:

Piancone F, Saresella M Marventano I, La Rosa F, Santangelo MA, Caputo D, Mendozzi L, Rovaris $M$ and Clerici $M$ (2018) Monosodium Urate Crystals Activate the Inflammasome in Primary

Progressive Multiple Sclerosis.

Front. Immunol. 9:983. doi: 10.3389/fimmu.2018.00983
Inflammasome-driven inflammation is postulated to play a role in multiple sclerosis (MS), but there is no direct evidence that the nod-like receptor protein 3 (NLRP3) inflammasome is involved in MS pathogenesis. Uric acid was shown to be one of the "danger" signals involved in the activation of NLRP3 inflammasome; notably, the concentration of uric acid is increased in the serum and in the cerebrospinal fluid of MS individuals. To better investigate the role of the NLRP3 inflammasome in MS-associated inflammation, we primed with lipopolysaccharide and stimulated with monosodium urate crystals PBMCs of $41 \mathrm{MS}$ patients with different disease phenotypes. Eleven individuals with primary progressive MS (PPMS), 10 individuals with stable relapsing-remitting MS (SMS), 10 individuals with acute relapsing-remitting MS (AMS), 10 individuals with benign MS were analyzed; 10 healthy controls were enrolled as well in the study. The expression of the NLRP3, apoptosis-associated speck-like protein containing CARD (ASC), caspase-1, caspase-8, IL-1 $\beta$, and IL-18 inflammasome genes was evaluated by RT-PCR. NLRP3 and ASC-speck protein expression was analyzed by FlowSight AMNIS, whereas production of the pro-inflammatory cytokines IL-1 $\beta$ and IL-18 and of caspase- 1 and caspase- 8 was measured by ELISA in supernatants. Results showed that uric acid serum concentration was significantly increased in PPMS; in these and in AMS patients, mRNA for NLRP3, ASC, and IL-18 was upregulated as well, but caspase-8 mRNA was upregulated only in PPMS. Expression of NLRP3 and ASC-speck protein was significantly increased in PPMS, SMS, and AMS patients, but IL-18 and caspase-8 production was significantly increased only in PPMS, in whom a direct correlation between hyperuricemia and caspase-8 was detected. The NLRP3/caspase-8 inflammasome pathway is activated in PPMS, possibly as a consequence of hyperuricemia. Therapeutic strategies reducing NLRP3 activation and/or lowering hyperuricemia could be useful in the therapy of PPMS.

Keywords: multiple sclerosis, inflammasome, uric acid, neuroinflammation, immunity

\footnotetext{
Abbreviations: MS, multiple sclerosis; NLRP3, nod-like receptor protein 3; CSF, cerebrospinal fluid; MSU, monosodium urate crystals; RR, relapsing-remitting; A, acute; S, stable; PP, primary progressive; B, benign; HC, healthy control; IL, interleukin; CNS, central nervous system; DAMP, damage-associated molecular pattern; ASC, apoptosis-associated speck-like protein containing CARD; EAE, experimental autoimmune encephalomyelitis; MRI, magnetic resonance imaging; EDSS, expanded disability status scale.
} 


\section{INTRODUCTION}

Multiple sclerosis (MS), the most common non-traumatic disabling neurological disease in young adults, is an inflammatory and demyelinating disease of the central nervous system (CNS) that is mediated by multiple immune effector mechanisms. From a pathogenic point of view, MS is a heterogeneous condition consisting of neuroinflammatory, autoimmune, and neurodegenerative processes that are the consequence of an inappropriate activation of the immune system toward myelin "self" antigens.

Similarly to other neurodegenerative diseases, MS is also characterized by complex biochemical alterations affecting neuronal functions. Uric acid, the product of purine catabolism, is a damage-associated molecular pattern (DAMP) released from dying cells whose concentration is reported to be elevated in the cerebrospinal fluid (CSF) and the serum of MS patients, in particular, in the chronic phase of the disease $(1,2)$. Notably, though, even if a correlation has been demonstrated between serum concentration of uric acid and susceptibility to the disease, hyperuricemia was not observed in every analyzed cohort of MS patients (3-8).

Uric acid activates the nod-like receptor protein 3 (NLRP3) inflammasome (9), an event suggested to be involved in the pathogenesis of MS. Inflammasomes are signaling complexes that sense inflammatory signals and promote inflammation by maturation and release of the pro-inflammatory cytokines interleukin (IL)-1 $\beta$ and IL-18. Classically, functional inflammasome complexes are composed of three proteins: a sensor (NLRP3, NLRP1, NLRC4, AIM2), an adaptor (apoptosis-associated specklike protein containing CARD (ASC)], and catalytic proteins (pro-caspase-1, pro-caspase-8). Upon detecting inflammatory signals, the inflammasome sensor molecule induces a rapid polymerization of the adaptor protein ASC into large helical filaments ("specks"), which represent the hallmark of inflammasome activation (10). The assembly of the three proteins results in the generation of a complex that mediates the self-cleavage of pro-caspase- 1 and pro-caspase- 8 to their active analogs. Caspase- 1 and caspase- 8 will then cleave the immature forms of the pro-inflammatory cytokines IL- $1 \beta$ and IL-18 into the mature bioactive forms.

Among the inflammasomes, much attention has been given to the NLRP3 complex due to its potential contribution to several diseases, including neurodegenerative conditions. The NLRP3 inflammasome can be activated by a wide range of stimulators, including pathogens, viruses, bacteria, extracellular ATP, amyloid $\beta$ and uric acid $(9,11,12)$. In experimental autoimmune encephalomyelitis (EAE), in particular, the most widely investigated animal model of MS, activation of the NLRP3 inflammasome was shown to have a critical role. Thus, augmented levels of caspase-1, IL-1 $\beta$, and IL-18 are observed in the pathogenesis of EAE (13) and, conversely, the absence of the NLRP3 gene results in diminished Th1 and Th17 encephalitogenic responses and reduces the inflammatory infiltrate in the spinal cord (14). Very recent results, in particular, show that, in caspase-1-deficient mice models, the processing and the release of IL-1 $\beta$ can be taken up by caspase- 8 (15). These data indicate that caspase- 8 , together with ASC and NLRP3, can drive IL-1 $\beta$ production in EAE and show the presence of a caspase-1-independent form of EAE (16). These results also suggest that caspase-1 activation may be not be present in all phenotypes of MS, which is a clinically heterogeneous disease.

In MS, it was shown that the upregulation of caspase-1, IL-1 $\beta$, and IL-18 associates with the progression and severity of disease (17-19). Caspase-1 expression, in particular, is elevated in MS plaques (20) and, together with that of IL-18, in peripheral mononuclear cells of MS patients (21). Notably, whereas augmented serum and CSF IL-18 concentration was shown to be present in MS individuals $(17,22)$, not all authors have found increases of IL- $1 \beta$ in the CSF of these patients (23-26). IL-1 $\beta$ is known to promote the differentiation of naive CD4+ T cells into Th17 T lymphocytes $(27,28)$, whereas IL-18 is a potent activator of polarized Th1 cells for IFN $\gamma$ production and lymphocytes proliferation (28). These observations are important within the pathogenesis of MS as both Th1 and Th17 T lymphocytes have been implicated in the pathology of the disease (29-32).

To verify whether NLRP3 activation could be detected in MS patients with different disease phenotypes, and to determine if hyperuricemia drives NLRP3 activation in MS, we analyzed uric acid serum concentration and NLRP3 inflammasome activation in MS patients affected by active MS or with a clinically quiescent disease.

\section{MATERIALS AND METHODS}

\section{Patients and Controls}

This study was approved by and carried out in accordance with the guidelines of the ethic committee of the Don Gnocchi Foundation and conformed to the Declaration of Helsinki. All participants gave informed consent according to a protocol approved by the local ethics of the Don Gnocchi Foundation.

Forty-one patients affected by MS as diagnosed by clinical and laboratory parameters, and followed by the Centro Sclerosi Multipla of the Don Gnocchi Foundation in Milano, Italy, were included in the study. Twenty patients (13 females and 7 males) were diagnosed as been affected by relapsing-remitting (RR) MS with or without sequelae. The disease had been clinically stable in 10 patients for at least 6 months prior to the study period; these patients (mean age $=45 \pm 11$ years; range $=26-62$ years; 7 females and 3 males) were classified as patients with stable relapsing-remitting MS (SMS). The diagnosis of SMS was confirmed by brain and spinal cord magnetic resonance imaging (MRI) with gadolinium: MRI showed no areas of enhancement at the time of enrollment. Mean disease duration was $20 \pm 10$ years (range $=1-31$ years); the median Kurtze Expanded Disability Status Scale $($ EDSS) score was 4.5 (range $=4-9$ ). Ten other RRMS patients (mean age $=46 \pm 13$ years; range $=28-69$ years; 6 females and 4 males) were undergoing clinical relapses of the disease and were classified as patients with acute relapsing-remitting MS (AMS). MRI scans performed during the acute phases showed enhancing lesions in all AMS patients. Mean disease duration was $19 \pm 15$ years (range $=4-39$ years); the median EDSS was 4.25 (range $=2-6$ ). Eleven patients (mean age $=60 \pm 10$ years; 
range $=48-72$ years; 5 females and 6 males) were diagnosed as been affected by PPMS; the MRI evidenced a stability of the lesion load at the time of enrollment. Mean disease duration was $16 \pm 10$ years (range $=5-36$ years); the median EDSS was 6 (range $=5.5-8$ ). Finally, 10 patients (mean age $=62 \pm 14$ years; range $=50-68$ years; 5 females and 5 males) were affected by benign MS (BMS); MRI showed stability or in many cases, an improvement of the lesion load at the time of enrollment. BMS was diagnosed based on the most widely accepted definition, i.e., an EDSS score $\leq 3.0>15$ years from the clinical onset of disease. Mean disease duration was $31 \pm 8$ years (range $=24-39$ years); the median EDSS score was 2 (range $=1-3$ ). None of the patients had received immunosuppressive drugs in the year prior to the study period.

Ten sex and age matched healthy controls (HC) (mean age $=53 \pm 5$ years; range $=42-58$ years; 8 females and 2 males) was enrolled as well in the study.

\section{Whole Blood and Serum Sample Collection and Cell Separation}

Thirty milliliters of whole blood was collected in EDTA-containing vacutainer tubes (Becton Dickinson and Co., Rutherford, NJ, USA). PBMCs were separated on lymphocyte separation medium (Organon Teknika Corp., Durham, NC, USA) and washed twice in PBS. Leukocytes viability was determined using a Bio-Rad TC20 Automated Cell Counter (Bio-Rad, CA, USA). Serum was collected in vacutainer tubes containing serum separator (Becton Dickinson and Co.). After $40 \mathrm{~min}$ at room temperature, samples were centrifuged at 3,000 rpm for $10 \mathrm{~min}$ to separate sera.

\section{Uric Acid Concentration in Sera}

Serum uric acid concentration was measured by the uricaseperoxidase method (Beckman Coulter Synchron LX, Beckman Coulter, Fullerton, CA, USA) following the manufacturer's instructions.

\section{Cell Cultures: Human Monocytic THP-1 Cell Line and PBMCs}

The human monocytic cell line THP-1 was provided by Istituto Zooprofilattico Sperimentale della Lombardia e dell'Emilia Romagna (Brescia, Italy) and maintained in RPMI 1640 supplemented with $10 \%$ fetal bovine serum, $2 \mathrm{mM} \mathrm{L}$-glutamine, and $1 \%$ penicillin (Invitrogen Ltd., Paisley, UK) (medium) at $37^{\circ} \mathrm{C}$ in a humidified $5 \% \mathrm{CO}_{2}$ atmosphere.

PBMCs were maintained in RPMI 1640 supplemented with $10 \%$ human serum, $2 \mathrm{mM}$ L-glutamine, and $1 \%$ penicillin (Invitrogen Ltd., Paisley, UK) (medium) at $37^{\circ} \mathrm{C}$ in a humidified $5 \% \mathrm{CO} 2$ atmosphere. THP-1 cells and PBMCs were resuspended at $1 \times 10^{6} / \mathrm{ml}$ and were either: (1) cultured in medium alone (unstimulated); or (2) primed $2 \mathrm{~h}$ with lipopolysaccharide (LPS) $(1 \mu \mathrm{g} / \mathrm{ml})$ (Sigma-Aldrich, St. Louis, MO, USA); or (3) stimulated with 50,100 , or $200 \mu \mathrm{g} / \mathrm{ml}$ of monosodium urate crystals (MSU) for $22 \mathrm{~h}$; and (4) primed $2 \mathrm{~h}$ with LPS and stimulated with 50, 100, or $200 \mu \mathrm{g} / \mathrm{ml}$ of $\mathrm{MSU}$ for $22 \mathrm{~h}$ at $37^{\circ} \mathrm{C}$ in a humidified $5 \% \mathrm{CO}_{2}$ atmosphere (33). LPS pre-incubation is required because neither NLRP3 nor pro-IL-1 $\beta$ are constitutively expressed and require transcriptional induction $(9,11,12)$. Each experiment was run at least in triplicate.

\section{Determination of the Optimal Dose of MSU to Be Used in Stimulation}

THP-1 cells and PBMCs stimulated with different concentration of MSU were evaluated for vitality with (3-4,5-dimethylthiazol2-yl-2,5-diphenyl-tretrazolium bromide) the MTT cell viability assay. Briefly, MTT dissolved in PBS was added to the cells $(20 \mu \mathrm{l} /$ well). Cells were incubated at $37^{\circ} \mathrm{C}$ for $22 \mathrm{~h}$, centrifuged, pellets were dissolved using $100 \mu \mathrm{l} /$ well of dimethyl sulfoxide, and plates were read in a micro plate reader using a test wavelength of $550 \mathrm{~nm}$ and a reference wavelength of $650 \mathrm{~nm}$. Results were calculated as: \% cytotoxicity $=100-[$ optical density $(\mathrm{OD})$ test $-\mathrm{OD}$ control] $/$ OD control $\times 100$. The concentration of $200 \mu \mathrm{g} / \mathrm{ml}$ of MSU was toxic to cells ( $>50 \%$ cell death); cell mortality was $<5 \%$ using $100 \mu \mathrm{g} / \mathrm{ml}$ of MSU, a dose that optimally stimulated the NLRP3 inflammasome (see Results).

\section{RNA Extraction and Reverse Transcription}

RNA was extracted from THP-1 cells or PBMCs using the acid guanidinium thiocyanate-phenol-chloroform method. RNA was dissolved in RNase-free water and purified from genomic DNA with RNase-free DNase (RQ1 DNase; Promega, Madison, WI, USA). One microgram of RNA was reverse transcribed into first-strand cDNA using RT2 First Strand kit (Qiagen, Hilden, Germany) according to manufacturer's instruction.

\section{Real-Time RT-PCR}

Quantitative real-time RT-PCR (qPCR) was performed on the Biorad CFX Real-Time PCR instrument (Biorad) using RT2 SYBR Green qPCR mastermix (Qiagen). All primers (NLRP3, ASC, caspase-1, caspase-8, IL-1 $\beta$, IL-18) (Qiagen) were cDNA specific. All the samples were evaluated for glyceraldehyde 3-phosphate dehydrogenase (GAPDH) expression by real-time PCR to test the quality of RNA. Results were expressed as $\Delta \Delta \mathrm{Ct}$ (where $\mathrm{Ct}$ is the cycle threshold) and are presented as ratios between the target gene and the GAPDH housekeeping mRNA.

\section{Image Stream Analysis by FlowSight AMNIS}

PBMCs $\left(1 \times 10^{6}\right)$, stimulated as described above, were fixed with $100 \mu \mathrm{l}$ of PFA (1\%) (BDH, UK), permeabilized with $100 \mu \mathrm{l}$ of Saponine (0.1\%) (Life Science VWR, Lutterworth, Leicestershire, LE), and stained with FITC-anti human NLRP3 (Clone \#768319, isotype Rat IgG2a, R\&D Systems, Minneapolis, MN, USA) and PE-anti human ASC (clone HASC-71, isotype mouse IgG1, Biolegend, San Diego, CA, USA) for $1 \mathrm{~h}$ at room temperature; cells were then washed with PBS, centrifuged at 1,500 rpm for $10 \mathrm{~min}$, resuspended in $50 \mu \mathrm{l}$ of PBS, and examined using the AMNIS Flowsight Imaging. Results were analyzed by IDEAS analysis software (Amnis Corporation, Seattle, WA, USA).

The analysis of NLRP3 expression was performed by internalization feature utilizing a mask representing the whole cell, defined by the brightfield image, and an internal mask defined by eroding the whole cell mask. 
Apoptosis-associated speck-like protein containing CARD speck formation was analyzed using the same mask of internalization feature, differentiating diffuse or spot (speck) fluorescence

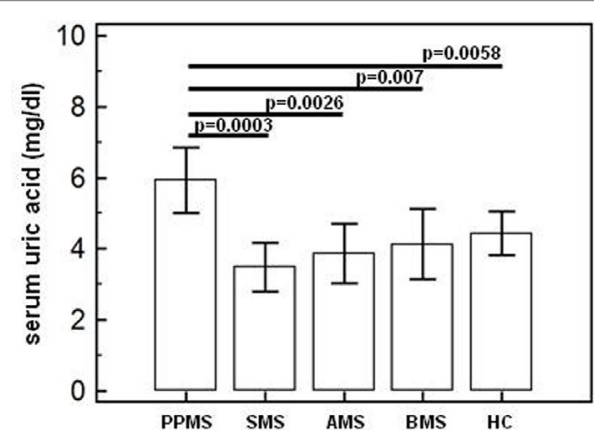

FIGURE 1 | Serum uric acid concentration. Uric acid concentration (means; mg/ dl) in serum of primary progressive (PP, $n=11)$, acute relapsing-remitting (A, $n=10)$, stable relapsing-remitting $(S, n=10)$, or benign $(B, n=10)$ multiple sclerosis (MS) patients and healthy controls $(\mathrm{HC}, n=10)$. SDs are indicated by vertical bars. Statistical significance is shown. inside of cells. Threshold mask was used to separate all ASC positive cells population in ASC-Speck spot cells or ASC-diffuse cells by the different diameter of the spot area: in ASC-speck, the spot shows a small area and high max pixel vice versa in cell with ASC-diffuse.

\section{ELISA}

IL-1 $\beta$, IL-18, caspase- 1 , and caspase- 8 concentration was determined by ELISA according to the manufacturer's recommendations (Quantikine Immunoassay; R\&D Systems) in supernatants from unstimulated or stimulated THP-1 cells and PBMCs. The wells were read on a plate reader (Sunrise, Tecan, Mannedorf, Switzerland) and optical density (OD) was determined at $450 / 620 \mathrm{~nm}$. The measured absorbance is proportional to the concentration of cytokines (IL-1 $\beta$ and IL-18) or caspases (caspase-1 and caspase-8) present in the supernatants expressed in picogram per milliliter and calculated by dividing OD measurement generated from the assay by OD cut-off calibrator. All the experiments were performed in triplicate.
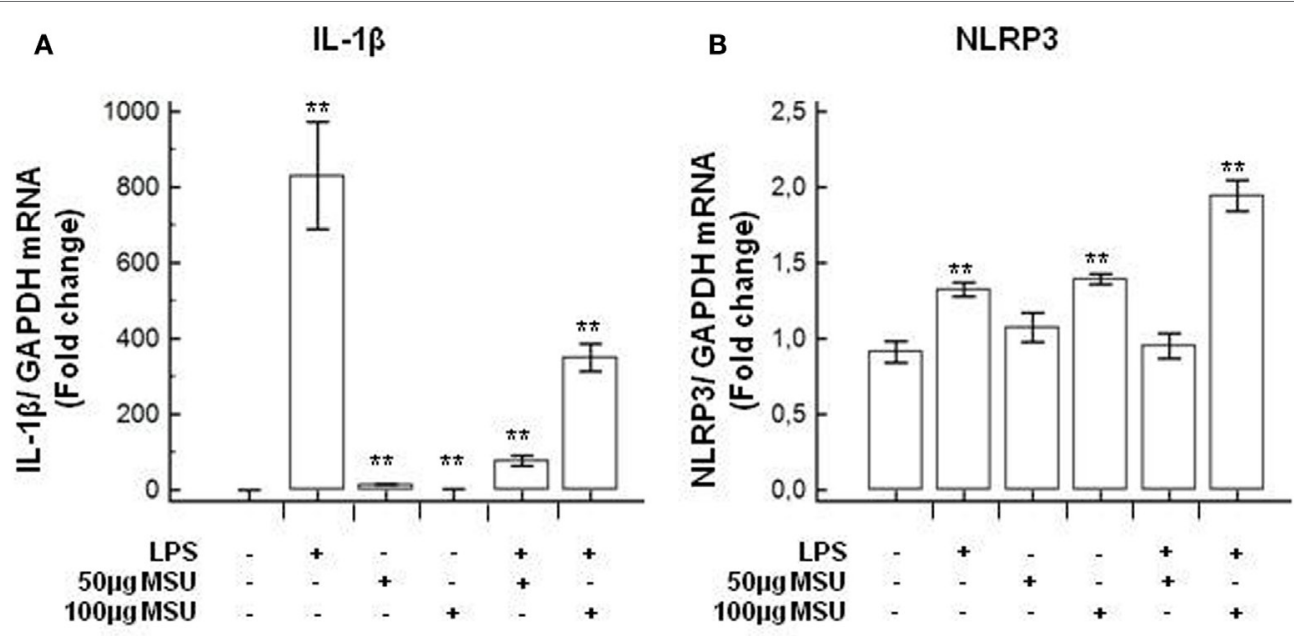

C

CASPASE-1
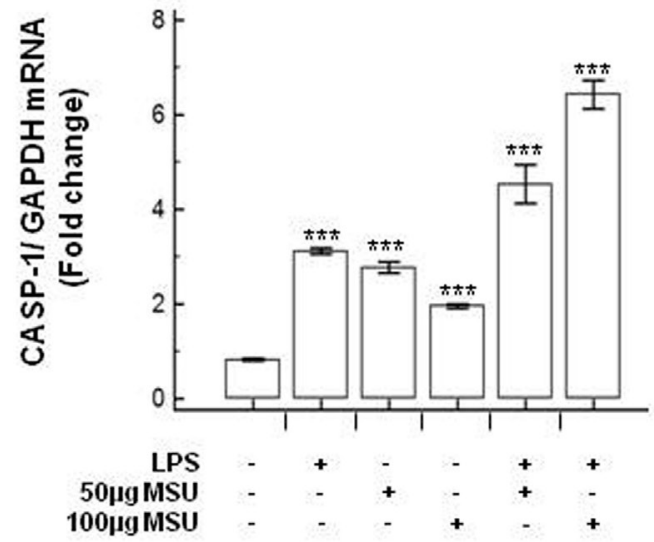

D

IL-18

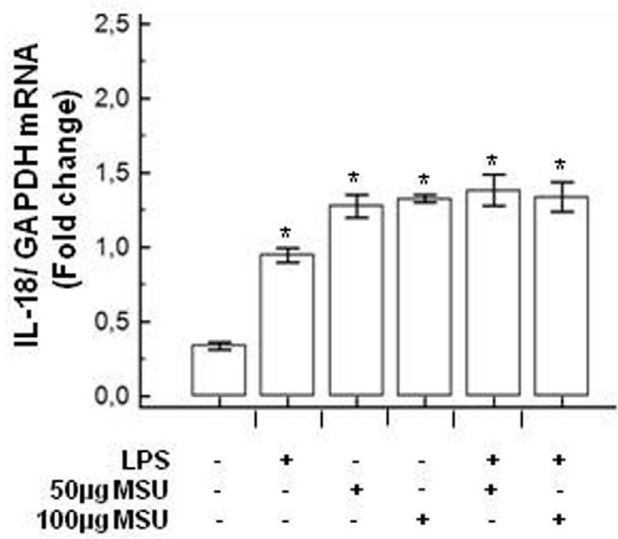

FIGURE 2 | Modulation of inflammasome genes by monosodium urate crystals (MSU) in THP1 cells. THP-1 cells were treated with lipopolysaccharide (LPS) (1 $\mu$ g/ $\mathrm{ml}$ ) for $2 \mathrm{~h}$ and/or with the indicate concentration of MSU crystals for $22 \mathrm{~h}$. RNA was isolated from THP-1 cells and the level of IL-1 1 (A), Nod-like receptor protein 3 (NLRP3) (B), Caspase-1 (C), and IL-18 (D) transcription was determined using SYBR green qPCR. Human GAPDH was used for normalization. 


\section{Statistical Analysis}

Quantitative data were not normally distributed (Shapiro-Wilk test) and are thus summarized as median and interquartile range. Comparisons between groups were analyzed used a Kruskal-Wallis ANOVA for each variable. Comparisons among the different groups were made using a 2-tailed Mann-Whitney $U$ test performed for independent samples. Acid uric serum data were normally distributed and were summarized as mean $\pm \mathrm{SD}$. In this case, comparisons were performed using ANOVA and unpaired Student's $t$-test. The statistical correlations between uric acid serum concentration and caspase- 8 protein were investigated using Spearman correlation coefficient and 95\% confidence limits performed by Fisher's $Z$ transformation.

Data analysis was performed using the MedCalc statistical package (MedCalc Software bvba, Mariakerke Belgium). p-Values of less than 0.05 were considered statistically significant.

\section{RESULTS}

\section{Uric Acid Serum Concentration}

Serum acid uric concentration was significantly increased in PPMS $($ mean $=6.0 \mathrm{mg} / \mathrm{dl} \pm 1.8)$ compared to the values observed in all others MS patients (AMS $=3.86 \mathrm{mg} / \mathrm{dl} \pm 0.79$, $\mathrm{SMS}=3.48 \mathrm{mg} / \mathrm{dl} \pm 0.74, \mathrm{BMS}=4.13 \mathrm{mg} / \mathrm{dl} \pm 1.17)$ and in $\mathrm{HC}$ (4.23 mg/dl \pm 0.61$)(p \leq 0.005$ for all comparison) (Figure 1).

\section{Modulation of Inflammasome Genes in LPS-Primed and MSU-Stimulated THP-1 Cells and in PBMCs}

To verify whether MSU stimulates the assembly of functional inflammasome complexes and to determine the optimal dose of MSU to be used in cell cultures, mRNA expression of NLRP3, caspase-1, IL-1 $\beta$, and IL-18 was evaluated in THP- 1 cells and in PBMCs of HC. Cells were unstimulated; stimulated with LPS alone; stimulated with 50, 100, or $200 \mu \mathrm{g} / \mathrm{ml}$ of MSU alone; or LPS-primed and stimulated with 50,100 , or $200 \mu \mathrm{g} / \mathrm{ml}$ of MSU. Results showed that the highest dose of MSU was toxic to the cells (mortality > 50\%). The two lower doses of MSU positively modulated these genes but a consistent upregulation of inflammasome related genes was observed in THP-1 cells stimulated with $100 \mu \mathrm{g} / \mathrm{ml}$ of MSU alone (Figure 2). This was further confirmed by measuring IL-18, caspase- 1 , and IL- $1 \beta$ concentration in supernatants of THP-1 cells (Figure 3). Results

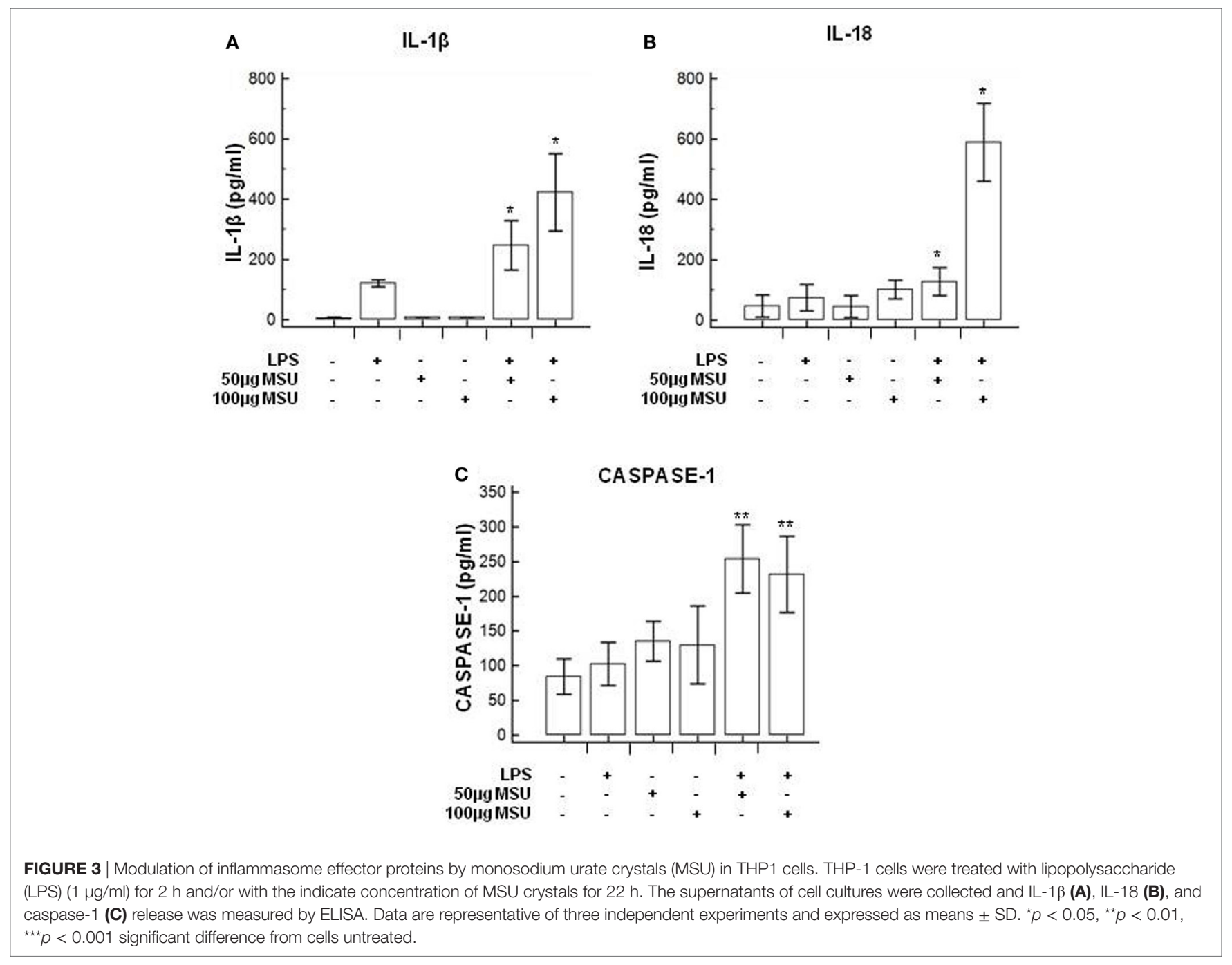


obtained when PBMCs of HC individuals were analyzed showed that the expression of inflammasome related genes (Figure 4), as well as the production of the inflammasome effector proteins (Figure 5) were only marginally upregulated. Based on these results, and on the lack of toxicity (cell death $<5 \%$ ), the concentration of $100 \mu \mathrm{g} / \mathrm{ml} \mathrm{MSU}$ was used to stimulate PBMCs obtained from patients.

\section{Modulation of Inflammasome Genes in LPS-Primed and MSU-Stimulated PBMCs of MS Subjects}

mRNA expression of NLRP3, ASC, caspase-1, caspase-8, IL-1 $\beta$, and IL-18, genes involved in the assembly, the activation, and the downstream signaling of inflammasomes was quantified by qPCR in all MS patients and controls. Data are expressed as the fold change (nFold) comparing results observed in unstimulated cells (medium) to those obtained in cells primed with LPS and stimulated with MSU $100 \mu \mathrm{g} / \mathrm{ml}$.

Results showed that, whereas inflammasome protein genes were not modulated in LPS-primed and MSU-stimulated PBMCs of $\mathrm{HC}$ and BMS individuals, these genes were significantly upregulated in cells of PPMS, AMS, and SMS patients. Notably, though the functional triad of inflammasome receptor (NLRP3), effector (ASC), and catalytic (caspase-8) genes was upregulated by MSU in PPMS alone: thus, the assembly of a potentially functional inflammasome complex was stimulated by MSU only in cells of MS patients with a primary progressive form of disease.

To summarize: (1) NLRP3 gene expression was significantly upregulated (nFold > 2) in PPMS, AMS, and SMS compared to HC $(p<0.05)$ (Figure 6A); (2) ASC was significantly upregulated in PPMS (nFold > 3.2) and AMS (nFold > 2.2) compared to all other groups of MS patients and HC $(p<0.005)$ (Figure 6B); and (3) caspase-8 expression was upregulated in PPMS (nFold $>2.5$ ) compared to all other groups of MS patients and HC $(p<0.05$ in all cases) (Figure 6C). Notably, no statistically significant differences were detected when caspase- 1 mRNA expression was analyzed (Figure 6D). These results seem to confirm that the inflammasome activity follows a caspase-1-independent pathway in PPMS-associated inflammation.

IL-1 $\beta$ and IL-18 gene expression was analyzed next in LPS-primed and MSU-stimulated PBMCs of all individuals. Results showed that IL-18 gene expression was significantly

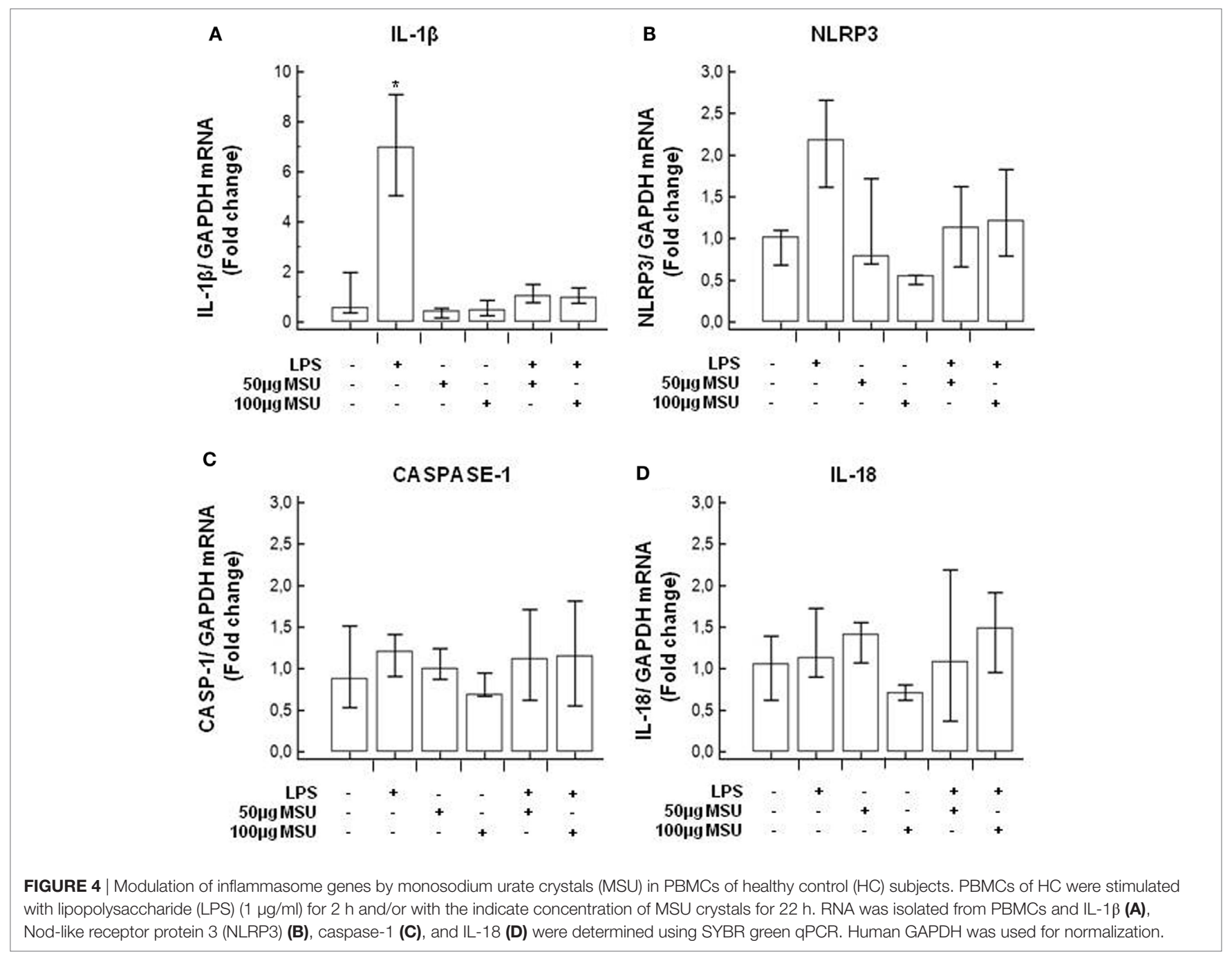


A

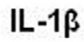

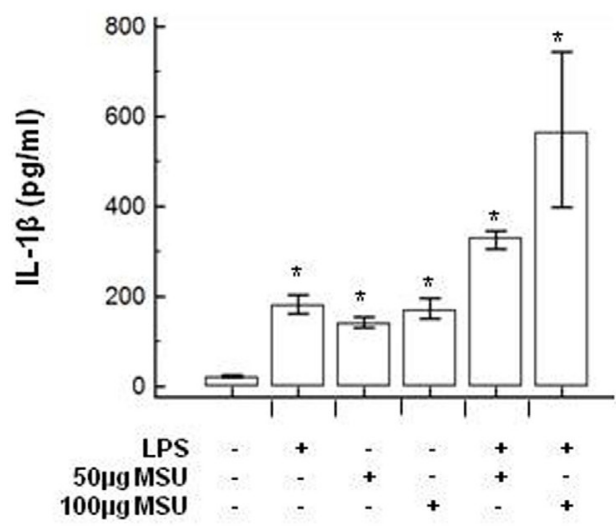

B

IL-18

C
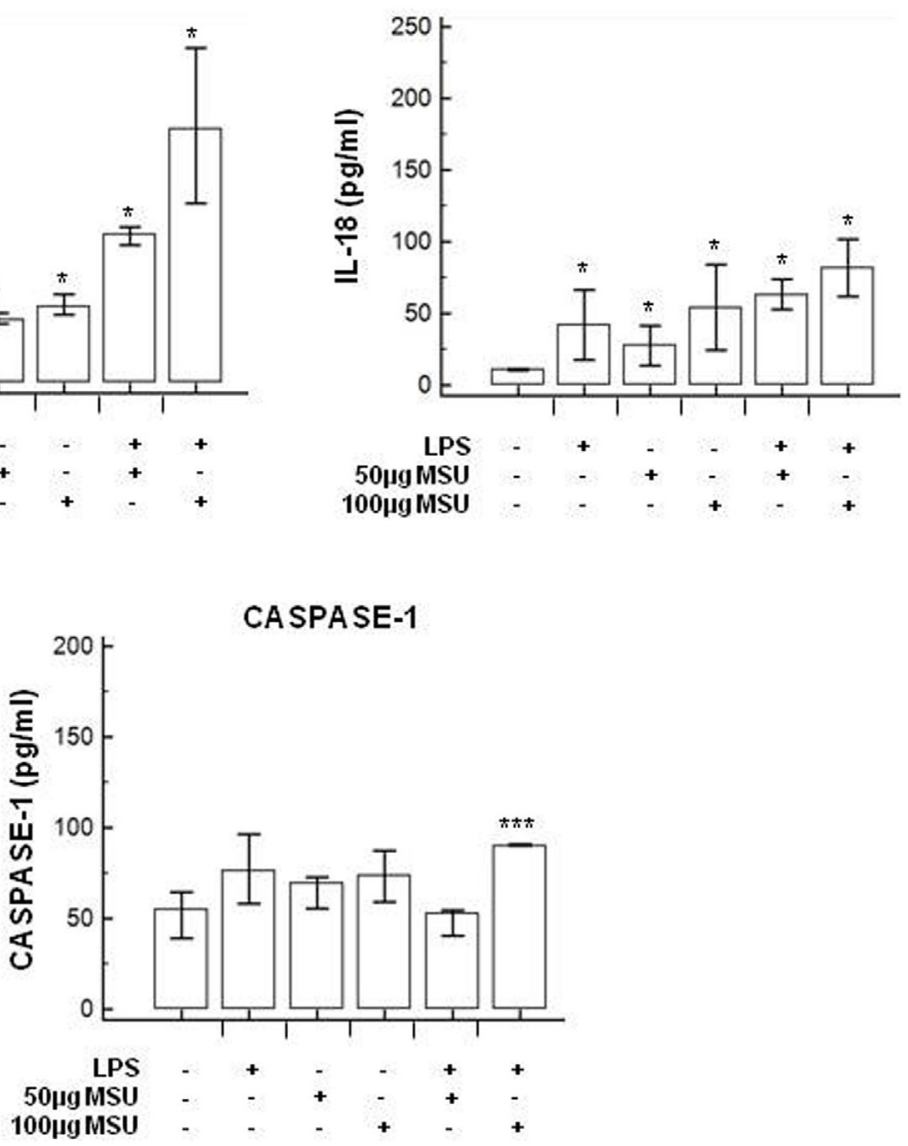

FIGURE 5 | Modulation of inflammasome effector proteins by monosodium urate crystals (MSU) in PBMCs of HC subjects. PBMCs of HC subjects were stimulated with lipopolysaccharide (LPS) $(1 \mathrm{\mu g} / \mathrm{ml}$ ) for $2 \mathrm{~h}$ and/or with the indicate concentration of MSU crystals for $22 \mathrm{~h}$. IL-1 $\beta$ (A), IL-18 (B), and caspase-1 (C) were quantified in supernatants by ELISA. Data are representative of three independent experiments and expressed as means \pm SD. ${ }^{*} p<0.05,{ }^{* *} p<0.01,{ }^{* \star *} p<0.001$ significant difference from cells untreated.

increased in PPMS (nFold > 4.6), AMS (nFold > 3), and SMS (nFold $>7.5$ ) compared to BMS and HC ( $p<0.05$ for all comparison) (Figure 6E). No statistically significant differences were detected when IL-1 $\beta$ mRNA expression was analyzed (Figure 6F).

\section{NLRP3 Production and ASC-Speck Formation in LPS-Primed and MSU- Stimulated PBMCs}

Nod-like receptor protein 3 production and ASC-speck formation were investigated next by Flowsight AMNIS analyses in LPSprimed and MSU-stimulated PBMCs of all patients and controls. Representative images are provided in Figures 7A-D.

Results from NLRP3 protein expression analysis confirmed that the percentage of cells expressing NLRP3 was significantly increased in PBMCs of PPMS, SMS, and AMS compared to those of $\mathrm{HC}$ ( $p<0.05$ for all comparison) (Figure 7E).

Apoptosis-associated speck-like protein containing CARDspeck formation, the hallmark of inflammasome activation, was then analyzed by Flowsight AMNIS in LPS-primed and MSU-stimulated PBMCs of all patients and controls. Results showed that the percentage of ASC-speck positive PBMCs was significantly increased in PPMS, SMS and AMS compared to BMS and HC ( $p<0.05$ for all comparison) (Figure 7F). Taken together, these results confirmed those obtained by gene expression analysis.

\section{Caspase-1, Caspase-8, and Inflammasome Effector Cytokines Production by LPS-Primed and MSU- Stimulated-PBMCs}

Caspase- 1 and caspase- 8 production by LPS-primed and MSUstimulated cells was evaluated next in all patients and controls. Results showed that, whereas caspase- 1 production was similar in all the groups of individuals (Figure 8A), caspase- 8 production was significantly increased in PPMS (median $=846 \mathrm{pg} / \mathrm{ml}$ ) alone compared to all other groups (Figure 8B). IL-1 $\beta$ and IL-18 production was analyzed as well in LPS-primed and MSU-stimulated 

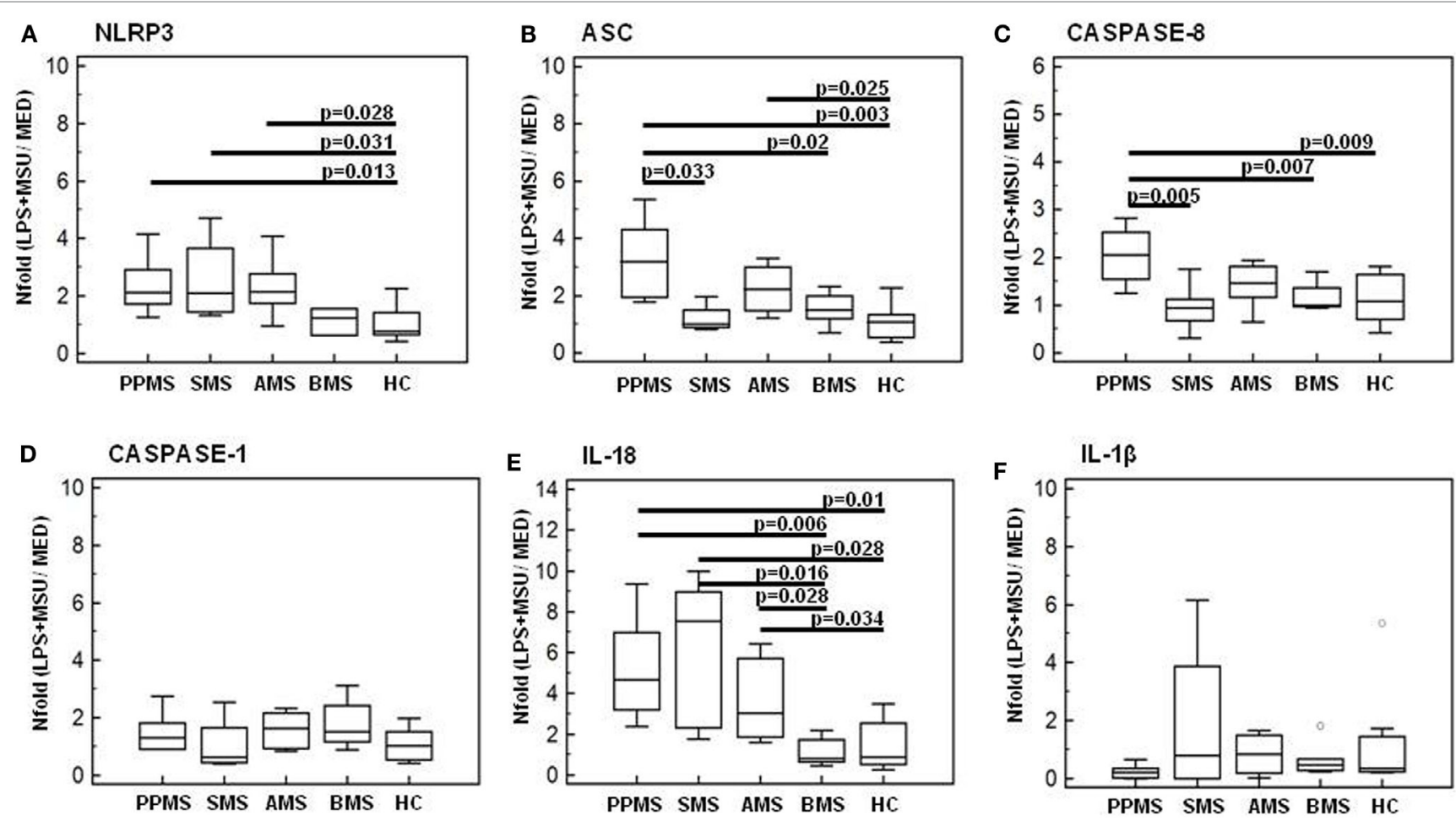

FIGURE 6 | Genes of inflammasome proteins in lipopolysaccharide (LPS)-primed and monosodium urate crystals (MSU)-stimulated PBMCs. mRNA expression by real-time PCR. Single real-time PCR results obtained in LPS-primed and MSU-stimulated immune cells of primary progressive (PP, $n=11)$, acute relapsing-remitting (A, $n=10)$, stable relapsing-remitting (S, $n=10)$, or benign (B, $n=10)$ Multiple sclerosis (MS) patients and healthy controls (HC, $n=10)$. Nod-like receptor protein 3 (NLRP3) (A), ASC (B), caspase-8 (C), caspase-1 (D), IL-18 (E), and IL-1 $\beta$ (F) mRNA levels are shown. The results are indicated as fold-change expression from the unstimulated samples. Summary results are shown in the bar graphs. The boxes stretch from the 25 to the 75 percentile; the line across the boxes indicates the median values; the lines stretching from the boxes indicate extreme values. Statistical significance is shown.

PBMCs. Once again, IL-18 was significantly increased in PPMS $($ median $=134 \mathrm{pg} / \mathrm{ml})$ alone (Figure $8 \mathrm{C})$. IL-18 production was not increased in AMS or SMS patients despite the upregulation of IL-18 mRNA that was detected in these individuals. This apparently puzzling result could be explained by the observation that, even if IL-18 mRNA levels are increased, the activation and the secretion of this cytokine are mediated by caspase- 8 , which was upregulated in PPMS patients alone.

Finally, IL-1 $\beta$ concentration was augmented in HC $($ median $=588 \mathrm{pg} / \mathrm{ml})$ alone compared to MS patients $(p<0.05$ vs. PPMS and BMS) (Figure 8D). These results confirm that, whereas IL-18 is elevated in MS, increased IL-1ß production is not always seen in this condition.

\section{Correlation Between Caspase-8 and Uric Acid Concentration}

Possible correlations between serum uric acid concentration and the production of the inflammasome proteins (caspase-1, caspase-8, IL-1 $\beta$, IL-18, ASC-speck, and NLRP3) were analyzed next (data not shown). Results showed that in PPMS, i.e., in those patients in whom hyperuricemia was detected, a significant positive correlation between serum uric acid concentration and active caspase- 8 protein is present $(\mathrm{R} p p=0.811, p<0.01)$ (Figure 9).

\section{DISCUSSION}

Multiple sclerosis is a neurodegenerative disease characterized by chronic inflammation; inflammasome-driven inflammation is postulated to play a role in MS, but as of today, there is no direct evidence that the NLRP3 inflammasome is involved in MS pathogenesis. MS is also characterized by a series of biochemical abnormalities that include increased serum and CSF concentrations of uric acid, a DAMP that is released from dying cells. Because the presence of hyperuricemia in MS is not confirmed by all authors, we first measured uric acid concentrations in serum of $41 \mathrm{MS}$ patients with different disease phenotypes comparing the results to those of age- and sex-matched HCs. Results showed that hyperuricemia is seen in primary progressive MS (PPMS) confirming previous data demonstrating an increase of uric acid in the chronic phase of the disease (34).

Uric acid can act as a DAMP and stimulate the assembly of the inflammasome and, thus, can be one of the culprits for the activation of inflammasome-dependent inflammation in MS $(9,35)$. Hence, we next analyzed whether stimulation of PBMCs of MS patients with monosodium urate crystals (MSU) would result in the transcription of inflammasome-related proteins and the production of the pro-inflammatory cytokines that are the end products of the functional assembly of such proteins. Results 
A

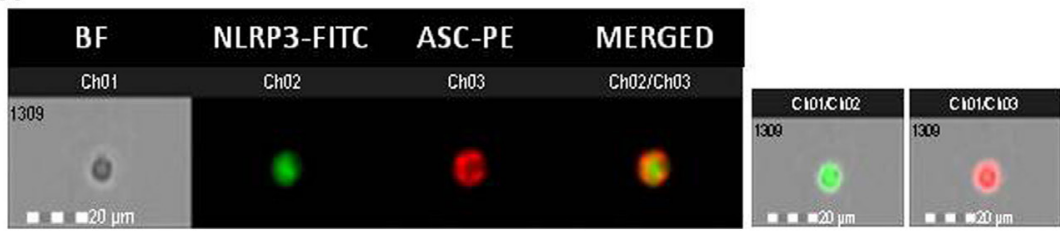

B

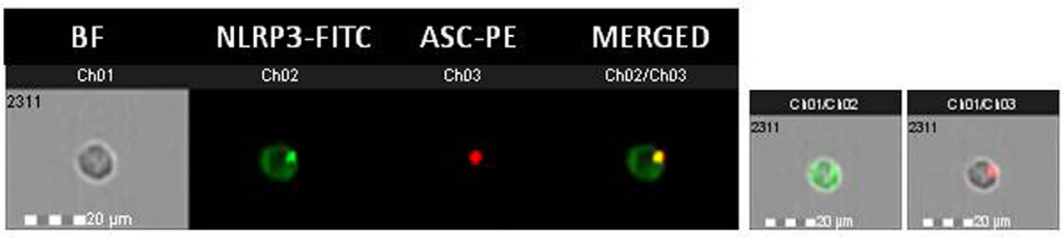

E

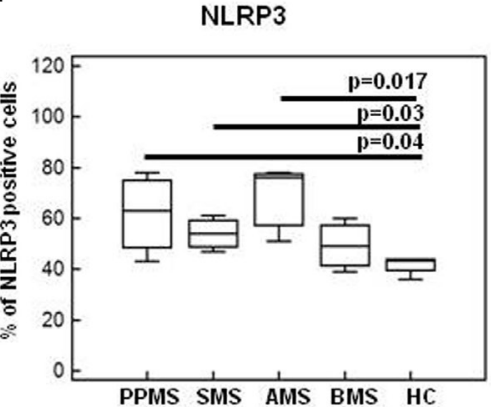

C

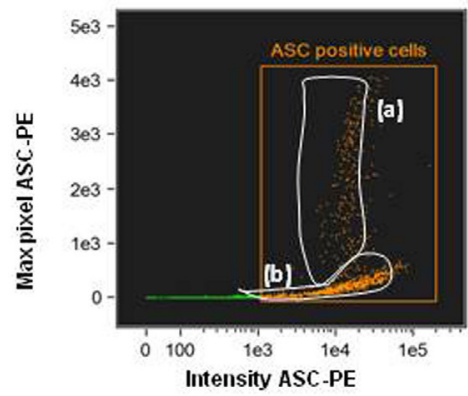

D

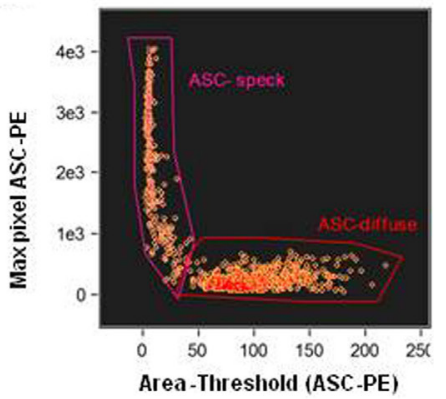

$\mathbf{F}$

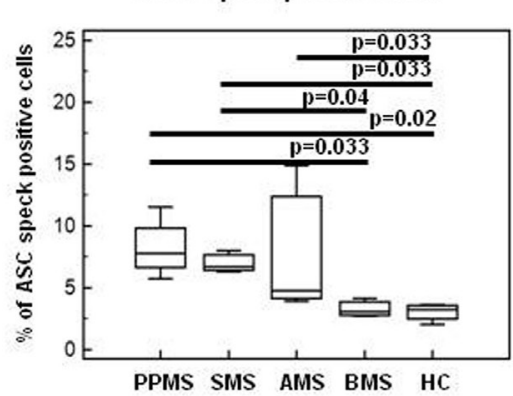

FIGURE 7 | Nod-like receptor protein 3 (NLRP3) expression and apoptosis-associated speck-like protein containing CARD (ASC)-speck formation in lipopolysaccharide (LPS)-primed and monosodium urate crystals (MSU)-stimulated PBMCs. Representative images of NLRP3 expression and ASC-speck formation in LPS-primed and MSU-stimulated PBMCs. [(A), ASC-diffuse; (B), ASC-speck]. The first column shows cells in brightfield (BF), second column shows NLRP3-FITC fluorescence, third column shows ASC-PE fluorescence, and fourth column shows florescence of ASC merged with NLRP3 (IDEA software). The percentage of ASC speck positive cells was performed using the same mask of internalization feature (C), differentiating spot (speck) or diffuse fluorescence inside of cells (DF): threshold mask was used to separate all ASC positive cells population in ASC-speck spot cells or ASC-diffuse cells by the different diameter of the spot area (D). In ASC-speck cell, the spot shows a small area and high max pixel, conversely, in ASC-diffuse cell, the fluorescence shows a large area and low max pixel. Summary results of NLRP3 (E) and ASC-speck positive cells (F) in LPS-primed and MSU-stimulated PBMCs of PPMS, SMS, AMS, BMS, and HC are shown in the bar graphs. The boxes stretch from the 25 to the 75 percentile; the line across the boxes indicates the median values; the lines stretching from the boxes indicate extreme values.

showed that, whereas the expression of inflammasome proteins was upregulated upon MSU stimulation in cells of patients with all forms of active disease, the functional triad of inflammasome receptor, effector, and catalytic proteins as well as IL-18, were significantly upregulated in PPMS alone.

The NLRP3 inflammasome is suggested to play a pivotal role in development of MS-associated neuroinflammation. Thus, in the EAE animal model of MS, Nlrp3 $3^{-/-}$mice are either resistant to the development of EAE, or, develop a delayed disease that is characterized by reduced severity $(14,17)$. Notably, diminished Th1 and Th17 encephalitogenic responses, diminished inflammatory infiltrate, and reduced spinal cord demyelination and gliosis are seen as well in Nlrp3 $3^{-/}$mice (14). In MS, results suggest the possible involvement of NLRP3 inflammasome in MS, but definite data are missing. Thus: (1) caspase-1, IL-1 $\beta$, and IL-18 upregulation was shown to associate with the progression and severity of disease (17-19); and (2) caspase-1 expression was observed to be elevated in MS plaques (20) and in peripheral mononuclear cells of MS patients (19). Results herein indicate that fully functional inflammasome complexes are assembled in PPMS and are likely to drive inflammation in these patients.

Nod-like receptor protein 3 inflammasome assembly leads to the production of pro-inflammatory cytokines; IL-18, in particular, is an inflammasome-derived cytokine whose concentration was observed to be augmented in serum and CSF of MS patients $(17,22,36)$. The possible involvement of this cytokine in the pathogenesis of MS was reinforced by the observations that IL-18 production by PBMCs of MS patients is increased (14) and that IL-18 is expressed by oligodendrocytes in brain tissues from patients with active MS (37). IL-18 plays an important role in Th1 response via its ability to induce IFN-gamma production in T lymphocytes and NK cells (38), and numerous reports confirm that Th1 responses directed toward self antigens are activated in MS (39-43). IL-18 is first synthesized as an inactive precursor; the precursor can be cleaved into the biologically active form of the protein, or can be stored intracellularly. Following its cleavage by caspases, the 
A

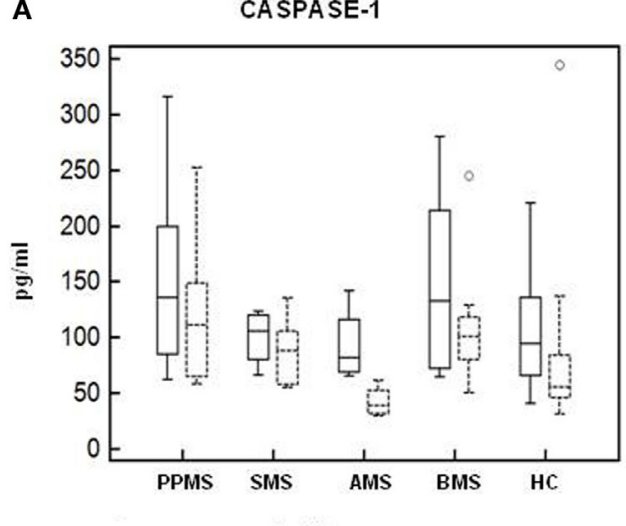

C

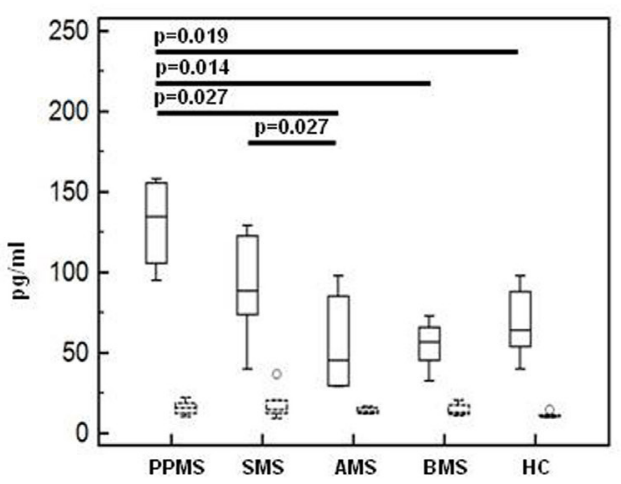

CASPASE-1

IL-18
D

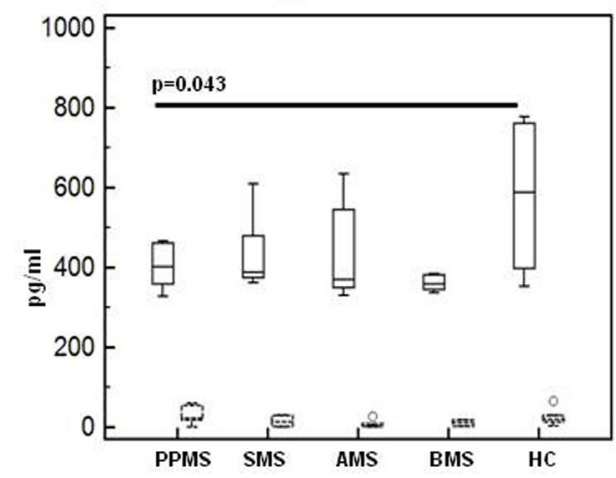

FIGURE 8 | Caspase-1, Caspase-8, and inflammasome effector cytokines production in lipopolysaccharide (LPS)-primed and monosodium urate crystals (MSU)-stimulated-PBMCs. Caspase-1 (A), Caspase-8 (B), interleukin-18 (C), and IL-1 $\beta$ (D) production was assessed by multiplex ELISA in supernatants of unstimulated and LPS-primed and MSU-stimulated cells of primary progressive (PP, $n=11)$, acute relapsing-remitting (A, $n=10)$, stable relapsing-remitting (S, $n=10)$, or benign $(\mathrm{B}, n=10)$ multiple sclerosis $(\mathrm{MS})$ patients and healthy controls $(\mathrm{HC}, n=10)$. Summary results are shown in the bar graphs. Solid lines represent supernatants from LPS-primed and MSU-stimulated cells. Dashed lines indicate supernatants from unstimulated cells. The boxes stretch from the 25 to the 75 percentile; the line across the boxes indicates the median values; the lines stretching from the boxes indicate extreme values.

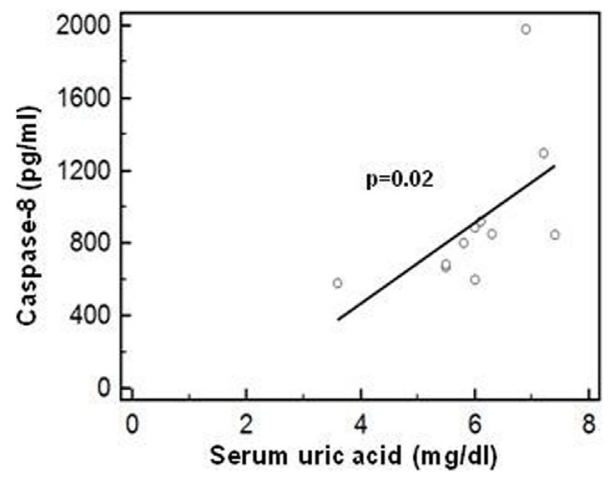

FIGURE 9 | Correlation between caspase-8 and uric acid concentration. Correlation between active caspase-8 protein (lipopolysaccharide-primed and monosodium urate crystals-stimulated PBMCs) and serum uric acid concentration in PPMS patients. Statistical significance is shown.

mature and biologically active form of IL-18 is secreted from monocytes/macrophages, even if over $80 \%$ of the IL- 18 precursor remains unprocessed inside the cell. Secreted IL-18 initiates multiple signaling pathways and drives inflammatory responses, which result in neuronal injury or death (44-47). The canonical NLRP3 inflammasome requires caspase- 1 activation for IL-1 $\beta$ and IL-18 processing. Recent results, nevertheless, indicate that $\mathrm{T}$ cell intrinsic inflammasome activity can drive IL- $1 \beta$ and IL-18 production via caspase- 8 activation independently from caspase- 1 activation $(48,49)$.

Our results showing that the expression of caspase- 8 but not of caspase-1 is significantly upregulated in PPMS alone, strongly suggest that a caspase-1-independent ASC-NLRP3caspase-8 inflammasome complex drives inflammation in PPMS patients.

Notably, IL-18 mRNA was significantly increased in MSUstimulated cells of PPMS, AMS, and SMS patients compared to the values seen in BMS or in HC; IL-18 production, nevertheless, was not augmented in these patients. The most likely explanation for this apparent discrepancy is that caspase- 1 was not modified in any of the groups examined and caspase-8, the "alternate" cleavage protein was augmented in PPMS alone; hence, only in these patients, the IL-18 precursor protein could be cleaved and the mature form of IL-18 could be secreted. Notably, assembly of functional NLRP3 inflammasomes did 
not result in significant changes in IL- $1 \beta$ mRNA expression and cytokine production in any of the groups examined. The existing literature on IL- $1 \beta$ expression in EAE and MS contains contradicting observations. Indeed: (1) most but not all authors have found increases of IL- $1 \beta$ in the CSF of MS patients (23-25) and (2) IL-1 $\beta$ staining was shown to be localized to resident microglia or differentiated macrophages but not to infiltrating monocytes, suggesting that IL- $1 \beta$ expression is induced within the CNS (50). Data herein seem to confirm these previous observations.

Taken together, our results suggest that in PPMS patients a possibly prolonged and chronic stimulation would result in the upregulation of mRNA expression of NLRP3, ASC, caspase-8, and IL-18 genes and of NLRP3, caspase-8, ASC-speck, and IL-18 proinflammatory cytokine; this could be justified by the observation that hyperuricemia is present in PPMS patients. Based on these data is tempting to speculate that, in PPMS, hyperuricemia would be responsible for the chronic activation of NLRP3 inflammasome and, as a consequence, the persistent activation of NF-Kb (51) and an excessive generation of pro-inflammatory cytokines. If this scenario is correct, therapeutic strategies aimed at reducing uric acid concentration and, as a consequence, downregulating inflammasome activity, might result in clinical benefit in these patients.

\section{REFERENCES}

1. Amorini AM, Petzold A, Tavazzi B, Eikelenboom J, Keir G, Belli A, et al. Increase of uric acid and purine compounds in biological fluids of multiple sclerosis patients. Clin Biochem (2009) 42(10-11):1001-6. doi:10.1016/j. clinbiochem.2009.03.020

2. Liu B, Shen Y, Xiao K, Tang Y, Cen L, Wei J. Serum uric acid levels in patients with multiple sclerosis: a meta-analysis. Neurol Res (2012) 34(2):163-71. doi:10.1179/1743132811Y.0000000074

3. Rentzos M, Nikolaou C, Anagnostouli M, Rombos A, Tsakanikas K, Economou M, et al. Serum uric acid and multiple sclerosis. Clin Neurol Neurosurg (2006) 108(6):527-31. doi:10.1016/j.clineuro.2005.08.004

4. Peng F, Zhang B, Zhong X, Li J, Xu G, Hu X, et al. Serum uric acid levels of patients with multiple sclerosis and other neurological diseases. Mult Scler (2008) 14(2):188-96. doi:10.1177/1352458507082143

5. Drulović J, Dujmović I, Stojsavljević N, Mesaros S, Andjelković S, Miljković D, et al. Uric acid levels in sera from patients with multiple sclerosis. J Neurol (2001) 248(2):121-6. doi:10.1007/s004150170246

6. Dujmovic I, Pekmezovic T, Obrenovic R, Nikolić A, Spasic M, Mostarica Stojkovic M, et al. Cerebrospinal fluid and serum uric acid levels in patients with multiple sclerosis. Clin Chem Lab Med (2009) 47(7):848-53. doi:10.1515/ CCLM.2009.192

7. Ashtari F, Bahar M, Aghaei M, Zahed A. Serum uric acid level in patients with relapsing-remitting multiple sclerosis. J Clin Neurosci (2013) 20(5):676-8. doi:10.1016/j.jocn.2012.05.054

8. Moccia M, Lanzillo R, Costabile T, Russo C, Carotenuto A, Sasso G, et al. Uric acid in relapsing-remitting multiple sclerosis: a 2-year longitudinal study. J Neurol (2015) 262(4):961-7. doi:10.1007/s00415-015-7666-y

9. Martinon F, Pétrilli V, Mayor A, Tardivel A, Tschopp J. Gout-associated uric acid crystals activate the NALP3 inflammasome. Nature (2006) 440(7081):237-41. doi:10.1038/nature04516

10. Tzeng TC, Tzeng TC, Schattgen S, Monks B, Wang D, Cerny A, et al. A fluorescent reporter mouse for inflammasome assembly demonstrates an important role for cell-bound and free ASC specks during in vivo infection. Cell Rep (2016) 16(2):571-82. doi:10.1016/j.celrep.2016.06.011

11. Mariathasan S, Weiss DS, Newton K, McBride J, O’Rourke K, Roose-Girma M, et al. Cryopyrin activates the inflammasome in response to toxins and ATP. Nature (2006) 440(7081):228-32. doi:10.1038/nature04515

\section{ETHICS STATEMENT}

The authors declare that the research was conducted in the absence of any commercial or financial relationships that could be construed as a potential conflict of interest.

\section{AUTHOR CONTRIBUTIONS}

FP, MS, and MC conceived and designed the research; FP, IM, FR, and MS performed the experiments; DC, LM, and MR are responsible for the clinical cohorts of patients; FP and MC analyzed the data and prepared the manuscript. All authors reviewed and approved the final manuscript.

\section{ACKNOWLEDGMENTS}

The authors thank all the subjects enrolled in the study; we are particularly grateful to Mrs. Raffaella De Pedrina and Mrs. Rosaria Trovato for the precious collaboration.

\section{FUNDING}

This research was supported by 2016-2017 Ricerca Corrente, Italian Ministry of Health.

12. Halle A, Hornung V, Petzold GC, Stewart CR, Monks BG, Reinheckel T, et al. The NALP3 inflammasome is involved in the innate immune response to amyloid-beta. Nat Immunol (2008) 9(8):857-65. doi:10.1038/ni.1636

13. Inoue M, Shinohara ML. NLRP3 inflammasome and MS/EAE. Autoimmune Dis (2013) 2013:859145. doi:10.1155/2013/859145

14. Gris D, Ye Z, Iocca HA, Wen H, Craven RR, Gris P, et al. NLRP3 plays a critical role in the development of experimental autoimmune encephalomyelitis by mediating Th1 and Th17 responses. J Immunol (2010) 185(2):974-81. doi:10.4049/jimmunol.0904145

15. Antonopoulos C, Russo HM, El Sanadi C, Martin BN, Li X, Kaiser WJ, et al. Caspase- 8 as an effector and regulator of NLRP3 inflammasome signaling. J Biol Chem (2015) 290(33):20167-84. doi:10.1074/jbc.M115.652321

16. Inoue M, Williams KL, Oliver T, Vandenabeele P, Rajan JV, Miao EA, et al. Interferon- $\beta$ therapy against EAE is effective only when development of the disease depends on the NLRP3 inflammasome. Sci Signal (2012) 5(225):ra38. doi:10.1126/scisignal.2002767

17. Losy J, Niezgoda A. IL-18 in patients with multiple sclerosis. Acta Neurol Scand (2001) 104:171-3. doi:10.1034/j.1600-0404.2001.00356.x

18. Karni A, Koldzic DN, Bharanidharan P, Khoury SJ, Weiner HL. IL-18 is linked to raised IFN-gamma in multiple sclerosis and is induced by activated CD4(+) T cells via CD40-CD40 ligand interactions. J Neuroimmunol (2002) 125:134-40. doi:10.1016/S0165-5728(02)00018-8

19. Mann CL, Davies MB, Stevenson VL, Leary SM, Boggild MD, Ko Ko C, et al. Interleukin 1 genotypes in multiple sclerosis and relationship to disease severity. J Neuroimmunol (2002) 129:197-204. doi:10.1016/S0165-5728(02)00181-9

20. Furlan R, Filippi M, Bergami A, Rocca MA, Martinelli V, Poliani PL, et al. Peripheral levels of caspase- $1 \mathrm{mRNA}$ correlate with disease activity in patients with multiple sclerosis; a preliminary study. J Neurol Neurosurg Psychiatry (1999) 67(6):785-8. doi:10.1136/jnnp.67.6.785

21. Huang WX, Huang P, Hillert J. Increased expression of caspase- 1 and interleukin18 in peripheral blood mononuclear cells in patients with multiple sclerosis. Mult Scler (2004) 10(5):482-7. doi:10.1191/1352458504ms1071oa

22. Chen YC, Chen SD, Miao L, Liu ZG, Li W, Zhao ZX, et al. Serum levels of interleukin (IL)-18, IL-23 and IL-17 in Chinese patients with multiple sclerosis. J Neuroimmunol (2012) 243(1-2):56-60. doi:10.1016/j.jneuroim. 2011.12.008

23. deJongBA,HuizingaTW,BollenEL,UitdehaagBM,BosmaGP,vanBuchemMA, et al. Production of IL-1beta and IL-1Ra as risk factors for susceptibility 
and progression of relapse-onset multiple sclerosis. J Neuroimmunol (2002) 126(1-2):172-9. doi:10.1016/S0165-5728(02)00056-5

24. Dujmovic I, Mangano K, Pekmezovic T, Quattrocchi C, Mesaros S, Stojsavljevic N, et al. The analysis of IL- 1 beta and its naturally occurring inhibitors in multiple sclerosis: the elevation of IL-1 receptor antagonist and IL-1 receptor type II after steroid therapy. J Neuroimmunol (2009) 207(1-2):101-6. doi:10.1016/j. jneuroim.2008.11.004

25. Tsukada N, Miyagi K, Matsuda M, Yanagisawa N, Yone K. Tumor necrosis factor and interleukin-1 in the CSF and sera of patients with multiple sclerosis. J Neurol Sci (1991) 104(2):230-4. doi:10.1016/0022-510X(91)90315-X

26. Maimone D, Gregory S, Arnason BG, Reder AT. Cytokine levels in the cerebrospinal fluid and serum of patients with multiple sclerosis. J Neuroimmunol (1991) 32(1):67-74. doi:10.1016/0165-5728(91)90073-G

27. Sato F, Martinez NE, Omura S, Tsunoda I. Heterogeneity versus homogeneity of multiple sclerosis. Expert Rev Clin Immunol (2011) 7:165-7. doi:10.1586/eci.11.3

28. Shaw PJ, McDermott MF, Kanneganti TD. Inflammasomes and autoimmunity. Trends Mol Med (2011) 17:57-64. doi:10.1016/j.molmed.2010.11.001

29. Saresella M, Tortorella P, Marventano I, Al-Daghri N, Piancone F, Gatti A, et al. TH17-driven inflammation is present in all clinical forms of multiple sclerosis; disease quiescence is associated with GATA3-expressing cells. Eur J Inflamm (2013) 11(1):223-35. doi:10.1177/1721727X1301100121

30. Volpe E, Battistini L, Borsellino G. Advances in T helper 17 cell biology: pathogenic role and potential therapy in multiple sclerosis. Mediators Inflamm (2015) 2015:475158. doi:10.1155/2015/475158

31. Jadidi-Niaragh F, Mirshafiey A. Th17 cell, the new player of neuroinflammatory process in multiple sclerosis. Scand J Immunol (2011) 74(1):1-13. doi:10.1111/j.1365-3083.2011.02536.x

32. Hedegaard CJ, Krakauer M, Bendtzen K, Lund H, Sellebjerg F, Nielsen CH. T helper cell type $1(\mathrm{Th} 1)$, Th2 and Th17 responses to myelin basic protein and disease activity in multiple sclerosis. Immunology (2008) 125(2):161-9. doi:10.1111/j.1365-2567.2008.02837.x

33. Braga TT, Forni MF, Correa-Costa M, Ramos RN, Barbuto JA, Branco P, et al. Soluble uric acid activates the NLRP3 inflammasome. Sci Rep (2017) 7:39884. doi:10.1038/srep39884

34. Tavazzi B, Batocchi AP, Amorini AM, Nociti V, D’Urso S, Longo S, et al. Serum metabolic profile in multiple sclerosis patients. Mult Scler Int (2011) 2011:167156. doi:10.1155/2011/167156

35. Gasse P, Riteau N, Charron S, Girre S, Fick L, Pétrilli V, et al. Uric acid is a danger signal activating NALP3 inflammasome in lung injury inflammation and fibrosis. Am J Respir Crit Care Med (2009) 179(10):903-13. doi:10.1164/ rccm.200808-1274OC

36. Nicoletti F, Di Marco R, Mangano K, Patti F, Reggio E, Nicoletti A, et al. Increased serum levels of interleukin-18 in patients with multiple sclerosis. Neurology (2001) 57(2):342-4. doi:10.1212/WNL.57.2.342

37. Cannella B, Raine CS. Multiple sclerosis: cytokine receptors on oligodendrocytes predict innate regulation. Ann Neurol (2004) 55(1):46-57. doi:10.1002/ ana.10764

38. Wawrocki S, Druszczynska M, Kowalewicz-Kulbat M, Rudnicka W. Interleukin 18 (IL-18) as a target for immune intervention. Acta Biochim Pol (2016) 63(1):59-63. doi:10.18388/abp.2015_1153

39. Balashov KE, Smith DR, Khoury SJ, Hafler DA, Weiner HL. Increased interleukin 12 production in progressive multiple sclerosis: induction by activated CD4+ Tcells via CD40 ligand. Proc Natl Acad Sci U S A (1997) 94(2):599-603. doi:10.1073/pnas.94.2.599

40. Bielekova B, Goodwin B, Richert N, Cortese I, Kondo T, Afshar G, et al. Encephalitogenic potential of the myelin basic protein peptide (amino acids
83-99) in multiple sclerosis: results of a phase II clinical trial with an altered peptide ligand. Nat Med (2000) 6(10):1167-75. doi:10.1038/80516

41. Grigoriadis N, van Pesch V; ParadigMS Group. A basic overview of multiple sclerosisimmunopathology.EurJ Neurol (2015) 22(Suppl2):3-13. doi:10.1111/ ene. 12798

42. Trabattoni D, Ferrante P, Fusi M, Saresella M, Caputo D, Urnovitz H, et al. Augmented type 1 cytokines and human endogenous retroviruses-specific immune responses in patients with acute multiple sclerosis. J Neurovirol (2000) 6(Suppl 2):S38-41.

43. Clerici M, Saresella M, Trabattoni D, Speciale L, Fossati S, Ruzzante S, et al. Single-cell analysis of cytokine production shows different immune profiles in multiple sclerosis patients with active or quiescent disease. J Neuroimmunol (2001) 121:88-101. doi:10.1016/S0165-5728(01)00431-3

44. Yatsiv I, Morganti-Kossmann MC, Perez D, Dinarello CA, Novick D, Rubinstein M, et al. Elevated intracranial IL-18 in humans and mice after traumatic brain injury and evidence of neuroprotective effects of IL18-binding protein after experimental closed head injury. J Cereb Blood Flow Metab (2002) 22(8):971-8. doi:10.1097/00004647-200208000-00008

45. Bossù $\mathrm{P}$, Ciaramella $\mathrm{A}$, Salani $\mathrm{F}$, Vanni $\mathrm{D}$, Palladino I, Caltagirone $\mathrm{C}$, et al. Interleukin-18, from neuroinflammation to Alzheimer's disease. Curr Pharm Des (2010) 16:4213-24. doi:10.2174/138161210794519147

46. Meissner F, Molawi K, Zychlinsky A. Mutant superoxide dismutase 1-induced IL-1 $\beta$ accelerates ALS pathogenesis. Proc Natl Acad Sci U S A (2010) 107:13046-50. doi:10.1073/pnas.1002396107

47. Wilms H, Sievers J, Rickert U, Rostami-Yazdi M, Mrowietz U, Lucius R. Dimethylfumarate inhibits microglial and astrocytic inflammation by suppressing the synthesis of nitric oxide, IL- $1 \beta$, TNF- $\alpha$ and IL- 6 in an in-vitro model of brain inflammation. J Neuroinflammation (2010) 7:30. doi:10.1186/1742-2094-7-30

48. Martin BN, Wang C, Zhang CJ, Kang Z, Gulen MF, Zepp JA, et al. T cell-intrinsic ASC critically promotes $\mathrm{T}(\mathrm{H}) 17$-mediated experimental autoimmune encephalomyelitis. Nat Immunol (2016) 17(5):583-92. doi:10.1038/ ni.3389

49. Pierini R, Perret M, Djebali S, Juruj C, Michallet MC, Förster I, et al. ASC controls IFN- $\gamma$ levels in an IL-18-dependent manner in caspase-1-deficient mice infected with Francisella novicida. J Immunol (2013) 191(7):3847-57. doi:10.4049/jimmunol.1203326

50. Burm SM, Peferoen LA, Zuiderwijk-Sick EA, Haanstra KG, 't Hart BA, van der Valk P, et al. Expression of IL- $1 \beta$ in rhesus EAE and MS lesions is mainly induced in the CNS itself. J Neuroinflammation (2016) 13(1):138. doi:10.1186/ s12974-016-0605-8

51. Dinarello CA, Novick D, Kim S, Kaplanski G. Interleukin-18 and IL-18 binding protein. Front Immunol (2013) 4:289. doi:10.3389/fimmu.2013. 00289

Conflict of Interest Statement: The authors declare that the research was conducted in the absence of any commercial or financial relationships that could be construed as a potential conflict of interest.

Copyright (๑ 2018 Piancone, Saresella, Marventano, La Rosa, Santangelo, Caputo, Mendozzi, Rovaris and Clerici. This is an open-access article distributed under the terms of the Creative Commons Attribution License (CC BY). The use, distribution or reproduction in other forums is permitted, provided the original author(s) and the copyright owner are credited and that the original publication in this journal is cited, in accordance with accepted academic practice. No use, distribution or reproduction is permitted which does not comply with these terms. 